\begin{tabular}{l|l|l|l}
\hline & $7_{=}^{\text {th }}$ CONGIC & Blucher Design Proceedings \\
$7^{\text {th }}$ CIDI & $\begin{array}{l}7^{\text {th }} \text { Information Design } \\
\text { International Conference }\end{array}$ & $\begin{array}{l}7^{\text {th }} \text { Information Design } \\
\text { Student Conference }\end{array}$ & $\begin{array}{l}\text { Setembro, 2015 }- \text { num. 2, vol.2 } \\
\text { proceedings.blucher.com.br }\end{array}$
\end{tabular}

\title{
New media perspectives for information and data design
}

Patricia Search

\begin{abstract}
multimedia design, metasyntax, cross-modal perception
Multimedia design can expand our awareness of data relationships in complex information spaces. Traditional Western design organizes information in structured hierarchies that restrict the way we interpret relationships. In today's information society, we need to represent information in fluid, holistic formats that challenge us to uncover new relationships using diverse spatial and temporal perspectives. We need to understand the semiotics of different media and the new semantic structures and metasyntax that result from cross-modal perception. This paper includes examples, created with an interactive art medium called HyperGlyphs, that illustrate new ways to incorporate unique design elements into engaging multimedia experiences. These examples encourage participants to explore dynamic information relationships from diverse perspectives that are outside the framework of Western logic. Graphics, sound, text, action, and reflective abstraction create a discursive environment that defines layers of sequential and simultaneous associations and kinaesthetic relationships that integrate the cognitive and sensory feedback from the interactive experience. During this interaction, multiple participants interact with the media, resulting in a dynamic social discourse that also adds new layers of meaning to the interpretation of the information.
\end{abstract}

\section{Introduction}

Information design requires innovative approaches to media design that support creative problem solving and new perspectives for information retrieval and analysis. Most interface designs reflect Western logic and design methodologies that emphasize hierarchical organizational structures and navigation. For complex information environments, including data analysis, it is important to explore new semiotic structures for interaction design that create flexible information spaces that help users synthesize information and develop a holistic approach to creative problem solving and information design.

Interactive multimedia design provides opportunities to explore ideas from diverse perspectives. To take full advantage of this potential, the interface design and organization of the information should encourage different ways of navigating and accessing information. Interactive art provides opportunities to explore new dimensions in information and interaction design. Through experimental art projects, it is possible to focus on the underlying relationships that shape our perception and understanding of multisensory design and the cross-modal semiotic structures that characterize interactive, multimedia environments. Weinbren (2007: 69) noted that 'Works of new media make the next step, by allowing multiple pathways through the database and permitting viewer input into, and control over, how individual paths are formed, accessed, and compounded.'

This paper outlines some design elements that augment traditional approaches to information design. Graphics, sound, text, and movement create interactive semiotic structures

P. Search. 2015. New media perspectives for information and data design. In: C. G. Spinillo; L. M. Fadel; V. T. Souto; T. B. P. Silva \& R. J. Camara (Eds). Anais [Oral] do 7을 Congresso Internacional de Design da Informação/Proceedings [Oral] of the 7th Information Design International Conference | CIDI 2015 [Blucher Design Proceedings, num.2, vol.2]. São Paulo: Blucher, 2015. ISSN 2318-6968, DOI 10.5151/designpro-CIDI2015-cidi_YY 
that we can leverage to produce intuitive designs that expand the potential for discovering new relationships in complex information spaces and data sets. The paper includes visual designs from an interactive art project that uses HyperGlyphs, a medium for creating interactive, audiovisual computer programs. The project explores the syntax of individual media and the metasyntax that emerges in these interactive environments. The examples highlight the perceptual and cognitive associations and spatiotemporal relationships that are integral to crossmodal design.

\section{New semantic structures}

Interactive multimedia design creates a new communication syntax that is derived from dynamic perceptual, cognitive, spatial, and temporal relationships. Our understanding of data relationships of all types, ranging from general information to detailed, numerical data, is shaped by this syntax.

In these multimedia environments, sound, motion, graphics, text, and interaction define the relationships and syntax between the elements. This dynamic environment defies the 'either/or' perspective that traditionally prevails in Western diachronic logic. It is a fluid space in which words, images, and sounds are transformed into a matrix of changing relationships. This transformation signifies the integration of past (what was), present (what is), and future (what will happen). The space between events is as important as the space where events actually happen. Monge and Kalman (1996: 74) pointed out that 'Space and time serve as the contexts in which all these communication entities exist and unfold.'

HyperGlyphs provide an alternative way to understand dynamic information and data relationships. This research is inspired by indigenous consciousness and how these peoples view relationships in physical and spiritual worlds. Similarly, this installation highlights the interaction of different 'worlds' or information/data relationships. The work also reflects the Japanese concept of $M A$ which defines space and time as an integrated whole that is perceived through a person's experience. Space becomes a moment in the continual process of change.

\section{Polysemiotic structures}

In HyperGlyphs, contrast in form, color, space, and transparency create integrated layers of spatial and temporal relationships that symbolize the multiple connections in complex information networks (Figure 1). Visual depth and spatial dimensions, created with transparency and multiple layers, suggest diverse perspectives, new possibilities, and the synthesis of elements and connections between ideas. In some places, positive shapes transform into 'ghosted' images or shadows that suggest the integration of the actual with the possible. Space folds into itself, uniting objects with the surrounding space. Events, as well as the space between the events, take on significance. The process of interaction creates patterns and rhythms that encode space and time into tangible representations of dynamic relationships and the transformation of ideas (Search. 2006). 
Figure 1. Transparency and layers symbolize the integration of information. Copyright 2014 Patricia Search. All rights reserved.

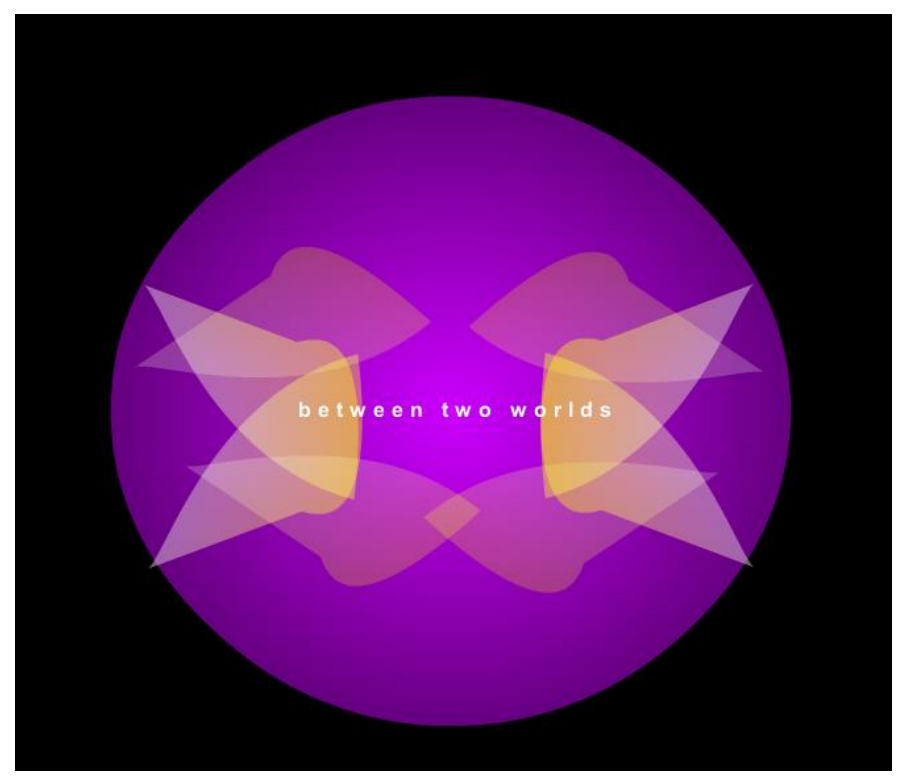

In HyperGlyphs, a polysemiotic semantic structure emerges and defines a discursive communication experience. Images, text, sound, and movement create an enactive, iconic, and symbolic space in which semiotic structures overlap and define a metasyntax that integrates the syntax of the different media (Search, 2011). The metasyntax creates a fluid semiosis by defining sensory and cognitive models that transcend the meaning of individual media or actions (Search, 2011). Parallel, synchronous formats co-exist with linear, sequential progressions. Causation is all-inclusive, not exclusive, leading to the holistic integration of diverse levels of detail, abstraction, and spatiotemporal relationships.

Turkle and Papert (1993) referred to this type of cognitive mapping of diverse perceptual responses as 'bricolage.' The combination of non-linear access to sensory information also results in what psychologists call reflective abstraction-a process that leads to generalizations through the synthesis of multiple perspectives (Piaget, 1977). Campbell (2001: 12) pointed out that reflective abstraction leads to 'constructive generalizations, to genuinely new knowledge, to knowledge at higher levels of development, and to knowledge about knowledge.' Memory also contributes to the abstraction and synthesis of information because viewers create mental landmarks. Memory creates a new type of experiential space that is based on sensory input and perception (Search, 2009). Referring to Patricia Hampl's essay titled 'Memory and Imagination,' McConkey (1996: 201) noted that memory connects answers 'to the abstract issues that underlie life itself.' 


\section{Sound}

Space and time are flexible entities that describe relationships between events. Sound can also expand our awareness of spatial and temporal relationships. Sound penetrates space and creates additional layers of depth. Sound, integrated with the display of graphics, creates an interactive dialogue that suggests multiple layers of associations and the flexible interpretation of ideas. Different types of sound-angular, linear, steady beats-can represent diverse data variables and relationships. Timbre, volume, and tempo are also audio dimensions that can be assigned to communicate specific variables or types of information.

Rhythm plays is an important element in multimedia design. There is the rhythm of the visuals, sound, movement of the graphics, and the movement of the viewer as s/he interacts with the programs using gestures, body movements, and/or physical interaction with the interactive hardware. Rhythm also occurs when audio and visual symbols that represent closure and continuity (e.g., circles, squares) contrast with shapes or sounds that suggest infinite time and space (e.g., straight lines, sustained sounds). The rhythm of the sound can vary from fluid, lyrical refrains to strong, steady beats. In information design, these unique rhythms can be used to represent different types of data and information relationships. Sounds that match the visual and rhythmic qualities of the graphics, animations, or transitions can underscore the cognitive and/or emotional connections communicated by the visuals. Sound can also create dissonance and contrast, and these design elements can highlight differences.

Sound and rhythm also communicate time. Seaman (2007: 130-131) pointed out that sensed time causes time to appear to move at different speeds:

When a work is being explored as a flowing movement through virtual space, time may appear to move at different speeds. Fragmentation can promote a feeling of the elongation of time-as one observes the different media-elements and processes displayed in the menu system ... Alternatively, the exploration of ambient audio loops prompts the feeling of a meditative 'suspension' of time.

\section{Interaction}

This cross-modal dialog is further enhanced in interactive multimedia design by the physical interaction of the participants who must move in specific ways to animate, display, and select information on the screen. The lines, space, and rhythms associated with these movements enable participants to engage in the interactive spatial representation of the data. These actions can create a rhythmic contrast to the movement of visuals and the audio, further emphasizing the potential for using cross-modal perception to define relationships in information design. The viewer may, for example, make curved, fluid movements or linear, angular movements. The rhythm of action also emphasizes the 'space' between the links and connections between ideas. Action defines the simultaneous existence of multiple spaces, times, and relationships. Action is more related to a state of existence than a particular event, object, time, or space.

This type of interaction design, called kinesthetic design, helps the viewer understand the visual and cognitive relationships in the spatial representation of information (Search, 2003). Berkeley (1922) demonstrated that kinesthetic and tactile experiences shape our perception of space. Klemmer, Hartmann, and Takayma (2006: 140) noted that that 'our bodies play a central role in shaping human experience in the world, understanding of the world, and interactions in the world.' When we physically interact with models or other tactile representations of data, we use reflective practice to work through ideas rather than just think about them (Klemmer, Hartmann \& Takayma, 2006). Researchers have also documented the significance of 'drawing' relationships in physical space with hand and arm movement to clarify conceptual relationships and enhance memory and recall (Fish \& Scrivener, 1990; Fish, 1993).

Anais [Oral] do 7º Congresso Internacional de Design da Informação | CIDI 2015 


\section{Multisensory design}

HyperGlyphs highlight the interconnection of polysemiotic semantic structures, cross-modal perception, kinesthetic design, and reflective abstraction for analysing and interpreting information. There is a level of determinism in the programming logic in the computer programs. However, that control is offset by the abstract, recursive nature of the curvilinear graphics, reflective text, and lyrical sounds that represent the open possibilities for defining new relationships through creative exploration of information and data sets. The HyperGlyph designs enable users to view information from outside the framework of narrative and causality by providing multidimensional ways of framing virtual information within the context of the user's tangible, physical environment.

With the HyperGlyphs installations, two participants interact with the graphics and sound from two different computer programs. The images from the programs are projected on top of each other, creating an immersive experience for the viewer. Free-form shapes are juxtaposed with geometric shapes to suggest different types of data, information, and relationships (Figure 2).

Figure 2. Geometric shapes and free-form elements symbolize different relationships. Copyright 2014 Patricia Search. All rights reserved.

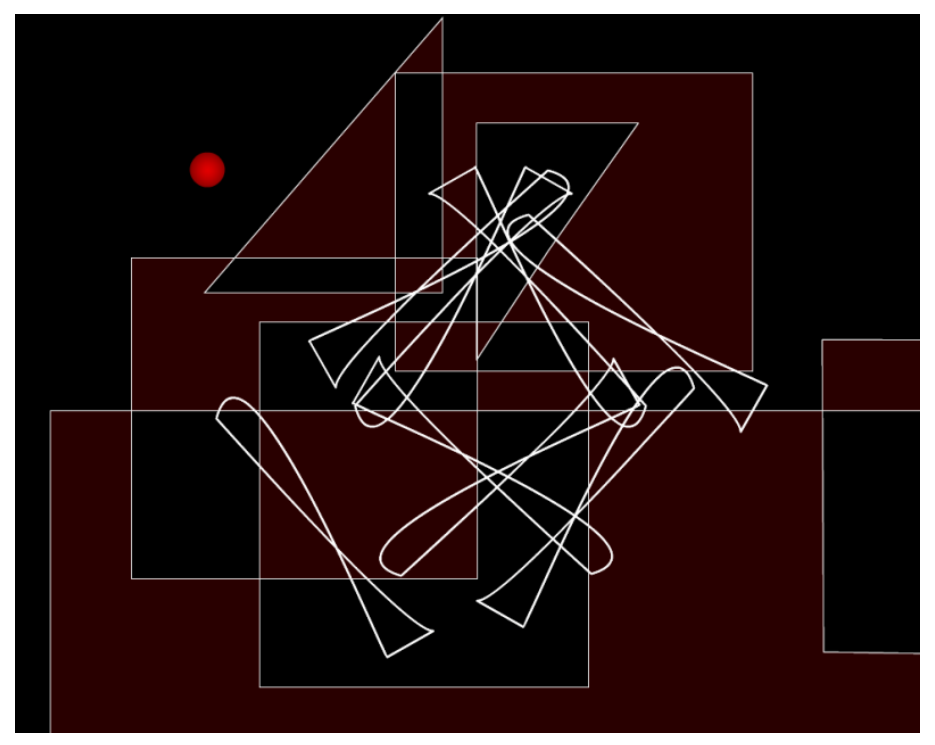

The viewer can rotate the individual forms in various ways to explore the relationships between shapes, lines, space, and time. As the elements move, they reveal new connections between the forms and sounds. Lines, text, numbers, filled shapes, and layers of transparency provide alternative perspectives and ways of interpreting these relationships. When the participants interact with the information, social discourse adds another layer of interpretation to the information space. The participants explore new relationships based on the actions of the other participant, and they discuss their individual perspectives as they navigate through the programs.

Silence between audio elements, blank spaces between graphics, and visual shapes and spaces defined by outlines suggest the possibility of combining and interacting with information in various ways. Figure 3 shows a screen design with numbers and linear graphics that symbolize discrete numerical data as well as ways to integrate information into a dynamic, cohesive whole. For example, the ' $x$ ' within a box is a symbolic representation of individual data. On the left, there 
is a space between the squares, which is a dynamic space that reveals another layer of text when the user moves over the space-suggesting the integration of information. Other interaction design elements also suggest this integration. For example, the Gestalt law of similarity prompts the viewer to group this set of graphics with the same visual (the "x" within a box) that appears on the right side of the screen. Participants can also move the large square, shown in the center of this example, around the screen and frame different numbers and graphics. This action symbolizes the potential for different combinations of information. The juxtaposition of visuals that represent structure (e.g., a grid of numbers, geometric shapes such as squares) with free-form elements reminds us that logic, order, and uncertainty are integral dimensions of information analysis. These visual symbols signify the potential for taking linear, structured ideas and combining them into dynamic, flexible relationships. Structure can be fluid and multidimensional, and finding ways to create this type of interactive space for information and data design can lead to new perspectives and innovative ways of exploring complex relationships.

Figure 3. Different types of graphics and the viewer's interaction symbolize the potential for transforming discrete data into dynamic relationships. Copyright 2014 Patricia Search. All rights reserved.

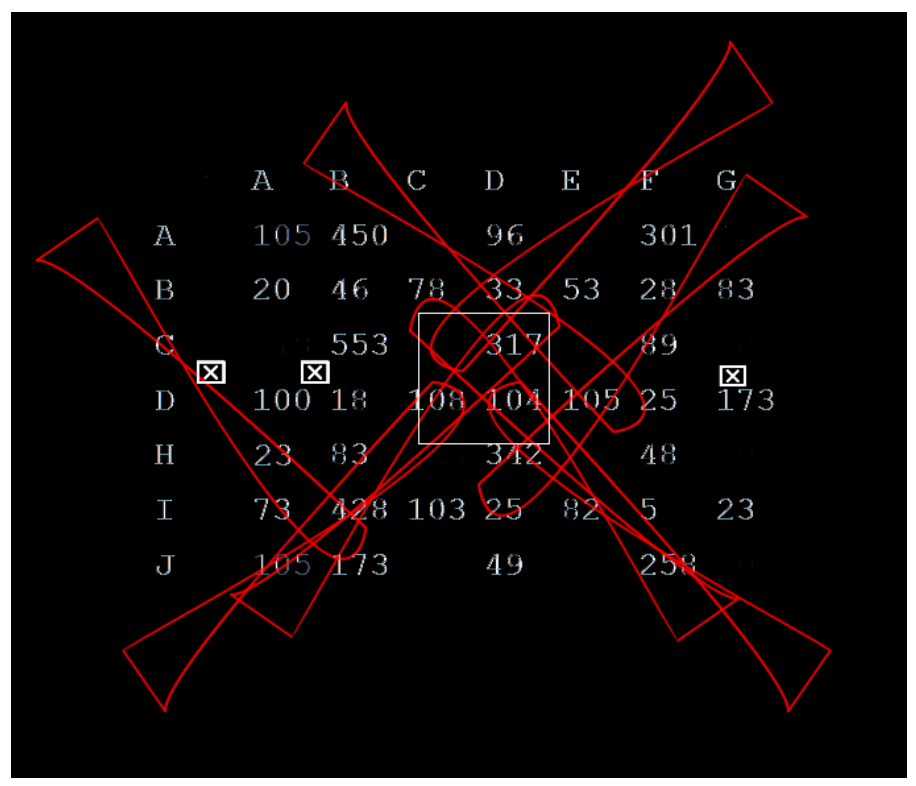

In this art installation, language is used as an abstract reference to time, space, sound, and the endless possibilities that exist for combining information into different relationships. Words such as now, then, and listen move apart, come together, overlap, and slide past each other, suggesting new ways to use space and time to define dynamic relationships.

Data exploration creates opportunities to experiment with audiovisual patterns in order to sharpen our perception of dynamic relationships and changes in the data. Patterns that collide, move apart, and morph into different shapes or colors can highlight critical transition points in the data relationships. Patterns that overlap and then separate also force us to experience the relationships from new perspectives. The process of selectively revealing parts of a visual or audio representation creates areas of focus that can highlight subtle changes that might not be easily recognized in a more complex context. In addition, initially exploring the audiovisual representation of select data or subsets of large data sets, rather than starting with all the data and anticipated outcomes, can lead to unexpected relationships and spatiotemporal representations. This element of 'surprise' can energize our senses and force us to reevaluate our approaches to analyzing the data. 
The surrounding physical environment also offers opportunities to change the way we look at complex relationships. In these art installations, images are projected on a blank wall with different types of fabric and physical objects positioned in front of the wall and projections. As the images fall into the folds of flowing fabric and wrap around the visual objects, the visuals become fully integrated into the physical space. The images change shape and form areas of shadow and highlight. They become information sculptures that remind us that data is more than just static, abstract numbers. Data can weave a matrix of dynamic relationships that tell stories and create important connections with individuals, groups, and the physical environment. These information sculptures remind us that we need to be attentive to those narratives as well as the discrete numerical information.

\section{Conclusion}

Multisensory design provides an opportunity to create alternative approaches to interactive design that channel our intuitive abilities to synthesize information so we can uncover new relationships and meaning. Layers of information can be combined into polysemiotic semantic structures that highlight both the simultaneous and sequential dynamics of complex information spaces. These design techniques encourage the viewer to explore diverse perspectives in defining and analysing relationships. Seaman (2007: 136) referred to this type of interaction with media and processes as field theory in which 'the participant, the environment, the interface system, audio processes and the media-elements explored through interaction determine meaning.' This approach to information design creates a fluid environment that reminds us that data is not static. It consists of multiple sets of changing relationships that are defined by context and the viewer's experience.

Interactive designs for representing complex data relationships should be fluid environments that present opportunities to explore data from different perspectives. To facilitate this process, it is important that the database be organized in a flexible format, and not a fixed, hierarchical structure, which has been the norm in Western database and information design. With flexible, ontologically flat databases, users are free to explore and define relationships between objects. Srinivasan and Huang (2005: 12) introduced the concept of 'metaviews' which evolve when users rearrange the database elements to define different perspectives and 'multiple, evolving ontologies.' Paul (2007) noted that meta-narratives emerge from the dynamic reorganization and exploration of the characteristics, organization, and cultural specifics of individual database elements.

Multimedia metadata is another element in database design that provides opportunities to use different media, not just text, to define and organize database information. Diverse media can take advantage of the iconic properties of visual and linguistic symbols and suggest different associations between database elements. The different media create multiple levels of perceptual encoding, spatial and temporal relationships, and cognitive associations (Search: 2015). Seaman (2007: 137) quoted Harris and Wolf's (1998: 1-2) description of integrational linguistics which notes that linguistic and non-linguistic signs are not mutually exclusive: 'Human beings do not inhabit a communication space which is compartmentalized into language and non-language, but an integrated space where all signs are connected.' Multimedia metadata can expand the potential for creating meaningful connections and narratives with complex data sets. By using different media, the senses provide another layer of interpretation to help us understand and relate to the underlying narratives, thus enabling data to take on social and cultural significance (Search: 2015).

The perspectives and approaches to information and data design presented in this paper add new dimensions to an important area of communication. On a daily basis, we use complex

Anais [Oral] do 7º Congresso Internacional de Design da Informação | CIDI 2015

Proceedings [Oral] of the 7th Information Design International Conference / IDIC 2015 
information and data sets to make critical decisions and policies in business, education, and government. It is important to use multiple design techniques to enhance our understanding of this information and communicate different perspectives to diverse audiences.

Multisensory designs in user interfaces, database organization, and metadata enable us to use different senses and perspectives to augment our perception and cognitive understanding of complex, dynamic relationships. We must be open to new design concepts and interactive tools that enable us to create and identify audio and visual patterns in different types of information spaces. New media art and design projects are unique resources that provide fresh perspectives for using multisensory design to create engaging information and data representations. These experimental applications expand our awareness of how visual, audio, and cross-modal semiotics define patterns that simplify and organize information. New technologies and applications that use multiple forms of sensory representation provide a window on the next generation of information and data design.

\section{References}

BERKELEY, G. (1922). A new theory of vision and other writings. New York: E. P. Dutton.

CAMPBELL, R. (2001). Studies in reflecting abstraction. Philadelphia: Psychology Press.

FISH, J. (1993). The cognitive functions of the sketch. Cheltenham, UK: Cheltenham \& Gloucester College of Higher Education, CAD Centre internal Report (May).

HARRIS, R. \& Wolf, G. (Ed.) (1998). Integrational linguistics: A first reader. New Orleans: Louisiana State University.

KLEMMER, S. R.; HARTMANN, B. \& TAKAYAMA, L (2006). How bodies matter: Five themes for interaction design. Proceedings of designing interactive systems: DIS 2006, 140-148.

McCONKEY, J. (Ed.) (1996). The anatomy of memory. Oxford: Oxford University Press.

MONGE, P. \& KALMAN, M. (1996). Sequentiality, simultaneity, and synchronicity in human communication. In: Watt, J. \& VanLear, C. A. (Ed.) Dynamic patterns in communication processes, 71-91. Thousand Oaks, CA: Sage Publications.

PAUL, C. (2007). In: Vesna, V. (Ed.) Database aesthetics: Art in the age of information overflow: 95-109. Minneapolis: University of Minnesota Press.

PIAGET, J. (1977). Recherches sur l'abstraction reflechissante, Vol. I \& II. Paris: Presses Universitaires de France.

SEAMAN, B. (2007). Recombinant poetics and related database aesthetics. In: Vesna, V. (Ed.) Database aesthetics: Art in the age of information overflow: 121-140. Minneapolis: University of Minnesota Press.

SEARCH, P. (2003). The metastructural dynamics of interactive electronic design. Visible language: Cultural dimensions of visual communications, 37(2): 146-165.

SEARCH, P. (2006). The spatial grammar of interaction design: Weaving a tapestry of space and time in multimedia computing. In: Griffin, R.; Cowden, B. \& Avgerinou, M. (Ed.) Animating the mind's eye: 184-190. Loretto, PA: International Visual Literacy Association.

SEARCH, P. (2009). A new visual literacy discourse for interactive electronic communication. In: Avgerinou, A.; Griffin, R.; Giesen, J. \& Search, P. (Ed.) Engaging creativity \& critical thinking: 181-188. Loretto, PA: International Visual Literacy Association.

SEARCH, P. (2011). Defining a sense of place in interactive multimedia design. In: Avgerinou, M.; Search, P. \& Chandler, S. (Ed.) Visual literacy in the $21^{\text {st }}$ century: Trends, demands, and capacities: 143-148. Chicago: International Visual Literacy Association.

Anais [Oral] do $7^{\circ}$ Congresso Internacional de Design da Informação | CIDI 2015

Proceedings [Oral] of the 7th Information Design International Conference / IDIC 2015 
SEARCH, P. (2015). Interactive multisensory data presentation. In: Proceedings of the International $\mathrm{HCl}$ International Conference. Coventry, UK: Springer.

SRINIVASAN, R. \& HUANG, J.: (2005). Fluid ontologies for digital museums. International Journal on Digital Libraries, 5(3): 193-204.

TURKLE, S. \& PAPERT, S. (1993). Epistemological pluralism and the evaluations of the concrete. In: Harel, I. \& Papert, S. (Ed.) Constructivism: 161-192. Norwood, NJ: Ablex Publishing Company.

WEINBREN, G. (2007). Ocean, database, recut. In: Vesna, V. (Ed.) Database aesthetics: Art in the age of information overflow: 61-85. Minneapolis: University of Minnesota Press.

\section{About the author}

Patricia Search, M.A., Rensselaer Polytechnic Institute, USA <searcp@rpi.edu> 